\title{
Improved impact performance of marine sandwich panels using through- thickness reinforcement: Experimental results
}

\author{
N. Baral ${ }^{a}$, D.D.R. Cartié ${ }^{b}$, I.K. Partridge ${ }^{b}$, C. Baley ${ }^{c}$ and P. Davies ${ }^{d, *}$
}

\author{
a CDK Technologies, Port la Forêt, F-29940 La Forêt Fouesnant, France \\ ${ }^{\mathrm{b}}$ Cranfield University, Cranfield, Bedford, MK43 OAL, UK \\ ${ }^{c}$ LIMAT B, Université de Bretagne Sud, 56100 Lorient, France \\ d IFREMER, Brest Centre, Materials \& Structures Group, 29280 Plouzané, France \\ *: Corresponding author: P. Davies, Tel.: +33 29822 4777; fax: +33 29822 4535, email address : \\ Peter.Davies@ifremer.fr
}

\begin{abstract}
:
This paper presents results from a test developed to simulate the water impact (slamming) loading of sandwich boat structures. A weighted elastomer ball is dropped from increasing heights onto rigidly supported panels until damage is detected. Results from this test indicate that honeycomb core sandwich panels, the most widely used material for racing yacht hulls, start to damage due to core crushing at impact energies around $550 \mathrm{~J}$. Sandwich panels of the same areal weight and with the same carbon/epoxy facings but using a novel foam core reinforced in the thickness direction with pultruded carbon fibre pins, do not show signs of damage until above $1200 \mathrm{~J}$ impact energy. This suggests that these will offer significantly improved resistance to wave impact. Quasi-static test results cannot be used to predict impact resistance here as the crush strength of the pinned foam is more sensitive to loading rate than that of the honeycomb core.
\end{abstract}

Keywords: A. Honeycomb; A. Three-dimensional reinforcement; B. Impact behaviour; D. Mechanical testing 


\section{Introduction}

Composite sandwich materials are widely used in marine structures, and honeycomb cored sandwich with thin carbon fibre reinforced epoxy facings is the standard choice for racing yacht hulls. The honeycomb core, composed of impregnated Nomex paper, shows excellent specific transverse compression and shear behaviour. However, hull structures are also subjected to so-called "slamming" loads caused by repeated water impacts. Several studies have described this phenomenon [1-3], which involves a localized pressure pulse travelling over a limited area of the hull. This can seriously damage sandwich structures, and is usually taken into account in design as an equivalent pressure [4]. However, there is considerable uncertainty over the safety factors required for this loading despite several measurement campaigns for different vessels (e.g. [5-7]). The slamming pulse is very short, typically lasting tens of milli-seconds, so special equipment is needed to record it and to correlate the recording with navigation conditions.

Two questions have been addressed in the present study; first, how can slamming impact be simulated in the laboratory, to enable new material combinations to be evaluated, and second, what are the material parameters which determine slamming resistance ? In the recent ISO procedure for dimensioning hull structures [4] a full size impact test is suggested to validate new designs. Such tests have been performed (e.g. [8]) but this is clearly a very expensive option. An intermediate alternative is to work on boat sections, and this approach has been used with drop tests to examine how pressure varies during a water impact on composite sandwich structures [9]. Small scale models have also been used in drop tests to obtain slamming pressure data [10], while a recent study used panels instrumented with Bragg gratings dropped into a wave tank [11]. At the laboratory scale various studies of rate effects on small core and sandwich coupons have been reported [12-15]. These provide useful input data for modelling but do not allow the influence of structural parameters such as panel thickness to be evaluated. Several other studies have focussed on rigid impacter loading of honeycomb sandwich materials (e.g. [16-18]) but a local indentation response is difficult to relate to the water impact of interest here. Furthermore, the damage induced in rigid impacter tests on honeycomb sandwich cannot be assumed to be independent of loading rate [16]. Finally, a very recent paper describes a test set-up specifically designed to examine controlled velocity impacts of panels on water, but this requires a complex dedicated test machine [19]. Various tests have been used at Ifremer to characterize impact behaviour of sandwich materials and a test involving dropping a weighted medicine ball on panels, from increasing heights, has been shown to simulate the type of damage found in practice [20]. For racing yachts the common use of very thin carbon composite skins (typically less than $1 \mathrm{~mm}$ thick) on lightweight honeycomb cores makes the structures susceptible to damage which appears as permanent core crushing. Medicine ball testing produces exactly this damage, Figure 1.

Given the existence of a suitable test, the nature of the damage observed after slamming impacts makes it useful to examine the many material parameters which may affect impact crushing resistance (core density, cell size, panel thickness...), and in particular to establish whether alternative core materials might offer improved performance for these structures. One option is a new type of pinned foam core, which comprises angled carbon pins in a foam core bonded to sandwich facings, and which can provide weight gains based on its quasistatic properties. These cores and an alternative in which the pins go through the facing composite, have been developed commercially recently for racing car and aerospace structures [21] see Figure 2. Fracture surfaces from out-of-plane tensile tests on pinned foam and on honeycomb sandwich panels are shown in Figure 3. It is clear that this form of core is completely different from the traditional honeycomb configuration and must be characterized in detail if its use is to be optimized. 
Marasco and colleagues have studied these materials in detail [22,23] , and Cartié and Fleck looked at rate effects [24] but few other data have been published to date to enable impact behaviour of pinned cores to be compared to that of honeycomb cores $[25,26]$. A principal aim of the current study was to make this comparison for panels subjected to a "soft" impact.

Finally, in order to optimise the design of sandwich structures and to avoid extensive large scale testing it is important to develop models which will allow parametric studies to be performed. This is an ongoing part of the present project, which will be presented later, but another reason for performing an instrumented series of tests such as those described below was to help to validate these models.

\section{Materials}

The sandwich materials which will be described here are of three types, Table 1 :

- Nomex honeycomb cores, with different densities from 48 to $96 \mathrm{~kg} / \mathrm{m}^{3}$. The basic core density studied is $64 \mathrm{~kg} / \mathrm{m}^{3}$, with hexagonal $5 \mathrm{~mm}$ cells, but other densities and forms were tested in the preliminary study to examine the influence of these parameters. Two forms of cell were examined, OX (over expanded) in the preliminary study, and hexagonal for the quasi-static and instrumented impact tests.

- Polyimide foam, from Rohacell, with density $31 \mathrm{~kg} / \mathrm{m}^{3}$

- Pinned foam, the same polyimide foam reinforced in the through-thickness direction with pultruded carbon fibre reinforced pins of $0.51 \mathrm{~mm}$ diameter in four directions at $+/-30^{\circ}$ to a normal to the facings (Figure 2 ). This resulted in an overall density of 64 $\mathrm{kg} / \mathrm{m}^{3}$.

All samples were supplied in the form of one metre square sandwich panels. The honeycomb sandwich materials were produced from Structil high strength carbon fibre R367-2 prepreg by curing in three steps, first one skin made up of two layers at $\pm 45^{\circ}$, then the honeycomb core was bonded to this using $300 \mathrm{~g} / \mathrm{m}^{2}$ ST1035 film adhesive, then a second film layer and the second $\left(+/-45^{\circ}\right)_{2}$ skin with mirror symmetry compared to the first. Cure conditions at each step were $100^{\circ} \mathrm{C}$ for 4 hours and 0.9 bar vacuum.

The foam and pinned reinforced foam panels were manufactured at Cranfield University. The $12 \mathrm{~mm}$ thick pin reinforced foam cores were manufactured inserting partially cured T650/epoxy carbon fibre rods using a 6 axis Kawasaki robot equipped with a dedicated insertion head, taking care to leave $5 \mathrm{~mm}$ lengths protruding from the foam. The protruding lengths were then bent and splayed out by pressing flat onto the surface of the cores using a hot press at $180^{\circ} \mathrm{C}$. The press was left to cool down slowly to room temperature, thus finishing the cure of the rods in the final shape. A $200 \mathrm{~g} / \mathrm{m}^{2}$ SA80 adhesive film was used between the cores and the skins. Each face sheet was made of two $\left( \pm 45^{\circ}\right)$ carbon/epoxy SE70 prepreg layers of $300 \mathrm{~g} / \mathrm{m}^{2}$ supplied by Gurit. The completed panels were cured at $120^{\circ} \mathrm{C}$ for two hours. The edges of the panels were reinforced with additional carbon/epoxy layers to avoid damage from the steel frame. 


\section{Test procedures}

\subsubsection{Quasi-static mechanical properties}

The quasi-static properties of the three types of sandwich were evaluated in compression (ASTM C365 on $50 \times 50 \mathrm{~mm}^{2}$ samples), tension (ASTM C297 on $50 \times 50 \mathrm{~mm}^{2}$ samples bonded to steel blocks), shear (ASTM C273 on $250 \times 50 \mathrm{~mm}^{2}$ samples with compression loading of samples bonded to steel rails). Three to five specimens were tested for each value. All tests were performed at a loading rate of $1 \mathrm{~mm} /$ minute.

\subsubsection{Soft impact}

A drop weight set-up was employed to study the impact response of one metre square sandwich panels. A preliminary series of tests was performed without instrumentation, followed by a series with full instrumentation.

\section{Boundary conditions}

The test set-up is shown in Figure 4 . The panel is rigidly clamped by 36 bolts using a torque wrench inside a two-part steel picture frame, which is in turn bolted to four load cells bolted between the frame corners and the ends of two rigid IPN bars. The $\pm 45^{\circ}$ facing fibres are aligned with the frame diagonal directions.

\section{Loading}

The panel is loaded by dropping a weighted elastomeric medicine ball from increasing heights until failure is detected visually. Two medicine balls of different weights were used. The first weighed $18.8 \mathrm{~kg}$ and was filled with sand, the second $26.3 \mathrm{~kg}$ and filled with steel particles. They were weighed before and after testing. Initial ball diameter is $280 \mathrm{~mm}$. The ball wall thickness is $10 \mathrm{~mm}$.

\section{Instrumentation}

The measurements made during these tests were:

- $\quad$ Impact loads, recorded by four load cells fixed between the corners of the test frame and the supporting IPNs. Their calibration was checked on a static test frame after testing. Values presented here are the sum of the four load cell values.

- Central panel displacement, measured by a laser displacement transducer placed on a support on the floor below the panel.

- Test frame displacement, measured at the frame mid-span by a second laser displacement transducer fixed to the floor. This value is subtracted from the central panel displacement to obtain the corrected panel displacement. Both lasers were checked by inserting calibrated spacer blocks before testing.

- $\quad$ Lower panel face strains, measured by three strain gauges at $0^{\circ}+45^{\circ}$ and $-45^{\circ}$. The $0^{\circ}$ direction is parallel to the frame edge and orthogonal to the support bars. These gauges were linked to a PC via three Sedeme dynamic amplifiers.

Ball shape and impact duration, using a high speed Photron Fast-Cam digital camera.

Rebound height using a Sony digital camera.

Three data acquisition systems were used in parallel. A Keithley data acquisition card linked to a PC and in-house software recorded the output from the two laser transducers and the three strain gauges. A Catman acquisition system also recorded the central laser signal, so that data from the acquisition systems could be co-ordinated, together with the four load cell signals. Both recorded at a rate of $10 \mathrm{kHz}$. Images from the high speed camera were recorded on a third PC at 2000 images per second. All data were stored for subsequent analysis. 


\section{Results and Discussion}

\subsubsection{Quasi-static tests}

The three materials were first characterized using standard quasi-static test procedures. Figure 5 shows an example of force-strain plots in compression; a comparison of the measured strengths of the three materials under compression, shear and tensile loading in standard tests is presented in Figure 6.

The quasi-static strength of the reference $64 \mathrm{~kg} / \mathrm{m}^{3}$ honeycomb core is higher than that of the pinned foam under both out-of-plane compression and shear loading. However, the through thickness tensile strength of the pinned foam is higher. The unreinforced foam properties are considerably lower than those of the two other sandwich materials but the density is also over $50 \%$ lower, so the comparison is not strictly valid.

\subsubsection{Soft impact tests}

Two series of tests were performed. The first was a preliminary series without instrumentation on sandwich panels with different variants of the core and geometry. The second, with the extensive instrumentation described above, provided a direct comparison between the basic $64 \mathrm{~kg} / \mathrm{m}^{3}$ honeycomb panel and the foam with and without pins.

Preliminary impact tests on honeycomb sandwich

Two examples from the preliminary tests, shown in Figure 7, enable the influence of sandwich thickness and density to be examined. The damage energy is the energy at which damage was observed, defined simply as $E=m g h$, with $m$ the mass of the impacter in $\mathrm{kg}$, $\mathrm{g}=9.81 \mathrm{~m} / \mathrm{s}^{2}$ and $\mathrm{h}$ the drop height in metres.

Thinner cores may provide improved impact performance due to improved deflection resulting in higher stored energy, Figure $7 \mathrm{a}$. Increasing density can improve the energy absorbed before damage is observed, as resistance to local crushing is improved, but there may be a plateau to this improvement as higher flexural rigidity results in lower deflection, Figure $7 \mathrm{~b}$. It should be noted that the thicker sandwich panels did not show the same damage mechanism as thin panels. For the latter core crushing was apparent, while thicker panels also showed skin/core delamination. Nevertheless the medicine ball test appears to be sensitive to material differences, therefore a more detailed series of tests was performed.

Instrumented test series

Four fully instrumented panels were tested, two honeycomb, one pinned foam core and one unreinforced core sandwich. Panels were loaded at drop height increments of one meter. In order to examine repeatability the two metre drop height test was repeated three times on each honeycomb panel. Table 2 shows the results, indicating good repeatability for energies below first damage. Figure 8 summarizes the tests performed on the three materials.

Figure 9 shows the damage incurred. The first damage of the standard $\left(64 \mathrm{~kg} / \mathrm{m}^{3}\right)$ material was noted visually after a drop from 3 metres, and sectioning revealed this to be permanent crushing of the core (Figure 9a). Visual damage of this type on a racing yacht would be repaired. No skin debonding was noted. A second identical panel was then tested to confirm this result and again first damage was noted at 3 metres. Tests were continued on this second panel up to final complete failure, which occurred at around $1.3 \mathrm{~kJ}$. 
The unreinforced polyimide core failed completely after an impact from one metre height, sectioning revealed core crushing and lower skin debonding in the core near the adhesive layer (Figure 9b). The pinned reinforced foam core was tested to a drop height of 6 metres with the $18.8 \mathrm{~kg}$ ball without any observable damage, then up to 5 metres with the $26.2 \mathrm{~kg}$ ball before final failure. This involved skin rupture with cracks following the $45^{\circ}$ fibres and along the frame edge as shown in Figure 9c. Sectioning of the central zone revealed no thickness change nor other indications of damage.

Figure 10 shows an example of the load and central displacement recordings for the honeycomb and pinned foam panel tests with 1 meter drops. The recordings are very similar for the two panels, suggesting that the difference in core does not affect the elastic behaviour of the structure. The impact duration is around 25 milliseconds in both cases.

Figure 11 presents the maximum loads and displacements recorded during the instrumented test series. These indicate that for the pinned foam the force and displacement increase fairly linearly up to final failure. For the honeycomb, the displacements are very similar initially but beyond the energy required for core crushing there is a break in the plots of both force and displacement, suggesting that the damage introduced has modified the response of the structure.

The force increases linearly with the impact energy, and hence with the drop height, but the deformable nature of the impacter means that the contact area may also change as drop height increases. The high speed camera enables the shape of the medicine ball to be observed during impact, and provides a qualitative indication of the contact zone. Pressure sensitive paper, which changes colour from white to red when pressure exceeds a threshold, has also been used to estimate the contact area. Paper with a very low threshold ( FujiFilm Ultra Super Low pressure film, threshold $0.2 \mathrm{MPa}$ ) was used. Figure 12 shows results from 11 tests on a range of undamaged panel materials including sandwich and monolithic materials, indicating that the contact area increases with impact height by about $10 \%$ per metre increase in drop height. However, this increase is quite small compared to the increase in measured force (Figure 11a), which is over $25 \%$ per metre increase, so the average pressure applied to the panel increases significantly with drop height.

The impact behaviour of composite plates depends on the duration of the event. Olsson has suggested a criterion to determine whether an impact can be considered as quasi-static, i.e. whether the impact is much longer than the time necessary for waves to reach the plate boundaries so the lowest vibration mode predominates [27]. The large impacter mass (18.8 $\mathrm{kg}$ ) compared to the panel mass $\left(3.6 \mathrm{~kg}\right.$ ) satisfies the $M / M_{p}>2$ criterion to suggest a quasistatic response, where $M_{p}$ is the total plate mass. High speed photography enabled a natural vibration frequency of around $100 \mathrm{~Hz}$ to be measured for the honeycomb and pinned foam panels.

The impact resistance of the pinned foam is significantly better than that of the honeycomb of equivalent density even though the quasi-static compression stress corresponding to permanent crushing of the latter is significantly higher. This result is very important, as the standardized compression and shear tests are generally used to classify materials for these applications. Also, if a problem is noted with a honeycomb cored panel in a critical area the response is usually to specify a higher density core there in order to increase the crush and shear strengths. The results shown here, both in the preliminary tests (Figure 7) and in the instrumented series, clearly indicate that this approach may not be appropriate. Changing to another core type, such as foam with through thickness pins, may be much more effective. While the global response of the panel may be quasi-static this does not mean that dynamic effects on yield and damage locally can be ignored. Indeed, given that the quasi-static compression properties do not correlate with the observed impact behaviour, this suggests that it is the rate dependence of the properties of these two types of core which differs, and that the pinned foam properties improve at high rates. Indeed, previous work by Cartie \& Fleck [24] has shown that compressive yield strength increased substantially for a lighter (31 $\mathrm{kg} / \mathrm{m}^{3}$ ) pinned foam core loaded at $10 \mathrm{~m} / \mathrm{s}$, almost double compared to quasi-static values. This was attributed to micro-inertia of the pins. Recent work on $48 \mathrm{~kg} / \mathrm{m}^{3}$ Nomex honeycomb has shown a much smaller increase in crush strength at high rates [15], possibly explaining 
the significantly better resistance of the pinned foam to impact damage. Further work is needed to explore this difference.

\section{Conclusions}

These tests clearly indicate that sandwich material with through-thickness pins offers great potential for improving the performance of structures subjected to water impact. A twofold increase in damage threshold under soft impact loading conditions was noted. The results from quasi-static compression tests alone do not provide a useful guide to slamming impact performance. The pin configuration tested here, based on one combination of pin angle, pin diameter and pin spacing, is probably not optimised and further improvements may be possible with other configurations. These results are now being used to validate a numerical model of impact response, in order to create of a tool to allow improved design of sandwich materials for these applications.

\section{Acknowledgements}

The authors wish to thank Gurit for the supply of facing materials for the foam and pinned reinforced foam cores part of this project. The supply of the Rohacell Foam by Degussa is also gratefully acknowledged.

\section{References}

[1] Sellars FH, Water impact loads, Marine Technology, (1976), 13, 1, 46-58.

[2] Hayman B, Haug T, Valsgard S, Response of fast craft hull structures to slamming loads, Prc. FAST'91, (1991), 381-388.

[3] Faltinsen OM, Hydroelastic slamming, J. Mar Sci Technol (2000), 5, 49-65.

[4] ISO/FDIS 12215-5, Hull construction - Scantlings - Part 5: Design pressure for monohulls, design stresses, scantlings determination, 2006.

[5] Baley C, Cailler M, Experimental and numerical behaviour of the structure of a $7.7 \mathrm{~m}$ sailing boat at sea, Proc. Int. Conf on Nautical Construction with Composite Materials, IFREMER publication ISBN 2905434449, 423-431.

[6] Aksu S, Price WG, Suhrbier KR, Temarel P, A comparative study of the dynamic behaviour of a fast patrol boat travelling in rough seas, Marine Structures, 6, 5-6, 1993, 421-441

[7] Manganelli P, Wilson PA, An experimental investigation of slamming on ocean racing yachts, Proc. $15^{\text {th }}$ Chesapeake Sailing Yacht Symposium, 2001.

[8] Baur P, Roy A, Casari P, Choqueuse D, Davies P, Structural mechanical testing of a full-size adhesively bonded motorboat, Proc. J. Engineering for the Maritime Environment, I Mech E 218 part M, (2004) 259-266.

[9] Hayman B, Haug T, Valsgard S, Slamming drop tests on a GRP sandwich hull model, Proc. $2^{\text {nd }}$ Int Conf on Sandwich Construction, EMAS, 1992.

[10] Zhu L, Faulkner D, Design pressure for wet-deck structure of twin-hull ships, Proc FAST 95, (1995) 257-268

[11] Jensen AE, Havsgard GB, Pran K, Wang G, Vohra ST, Davis MA, Dandridge A, Wet deck slamming experiments with a FRP sandwich panel using a network of 16 fibre optic Bragg grating strain sensors, Composites Part B, 31, (2000) 187-198.

[12] Feichtinger KA, Test methods and performance of structural core materials -IIA-Strain rate dependence of shear properties, Composites, No 1, Jan-Feb (1991), 37-47.

[13] Van Gellhorn E, Reif G, Think dynamic - Dynamic test data for the design of dynamically loaded structures, Proc Sandwich Constructions 2, EMAS (1992) 541-557. 
[14] Davies P, Baizeau R, Wahab A, Pecault S, Collombet F, Lataillade J-L, Determination of material properties for structural sandwich calculations: from creep to impact loading, Mechanics of Sandwich Structures, ed Vautrin A, 1998, Kluwer Publishers.

[15] Heimbs S, Schmeer S, Middendorf P, Maier M, Strain rate effects in phenolic composites and phenolic impregnated honeycomb structures, Comp Sci \& Tech, 67 (2007) 2827-2837.

[16] Herup EJ, Palazotto AN, Low velocity impact damage initiation in graphite/epoxy/nomex honeycomb sandwich plates, Comp Sci \& Tech, 57 (1997) 1581-1598.

[17] Meo M, Vignjevic R, Marengo G, The response of honeycomb sandwich panels under low velocity impact loading, I J Mech Sci 47, (2005) 1301-1325.

[18] Andersen T, Madenci E, Experimental investigation of low velocity impact characteristics of sandwich composites, Comp. Structures, 50 (2000) 239-247.

[19] Downs-Honey R, Erdinger S, Battley M, Slam testing of sandwich panels, SAMPE Journal, 42, 4 (2006) 47-55.

[20] Choqueuse D, Baizeau R, Davies P, Experimental studies of impact on marine composites, Proc ICCM12, (1999), Paris.

[21] Carstensen, T., Cournoyer, D. Kunkel, E. Magee, C. (2001) 'X-Cor Advanced Sandwich Core Material', in Proceedings of the 33rd International SAMPE Technical Conference at Seattle, USA

[22] Marasco AI, Cartié DDR, Partridge IK, Rezai A, Mechanical properties balance in novel Z-pinned sandwich panels : Out-of-plane properties, Composites Part A, 37 (2006), 295-302.

[23] Marasco Al, Analysis and evaluation of mechanical performance of reinforced sandwich structures : X-cor ${ }^{\mathrm{TM}}$ and K-cor ${ }^{\mathrm{TM}}$. PhD thesis Cranfield University, (2006).

[24] Cartie DDR, Fleck NA, The effect of pin reinforcement upon the through-thickness compressive strength of foam-cored sandwich panels, Comp. Sci \& Tech, 63 (2003), 2401-2409.

[25] Palazotto AN, Gummadi LNB, Vaidya UK, Herup EJ, Low velocity impact damage characteristics of Z-fiber reinforced sandwich panels - an experimental study, Comp Structures (1999) 275-288.

[26] Vaidya UK, Nelson, Sinn B, Mathew B, Processing and high strain rate impact response of multifunctional sandwich composites, Composite Structures, 52, 3-4 (2001), 429-440.

[27] Olsson R, Mass criterion for wave controlled impact response of composite plates, Composites Part A, 31, (2000), 879-887. 
Tables

\begin{tabular}{|l|l|l|l|l|}
\hline Reference & Core & Facing resin & Film adhesive & Fabrication \\
\hline Nomex & $\begin{array}{l}64 \mathrm{~kg} / \mathrm{m}^{3}, 12 \mathrm{~mm} \text { thick } \\
\text { OX and Hexa }\end{array}$ & R367-2 Structil & ST1035 & Oven $100^{\circ} \mathrm{C}$ \\
\hline Foam & Rohacell 31, 12mm thick & SE70 Gurit & SA80 & $\begin{array}{l}\text { Autoclave 1 atm } \\
120^{\circ} \mathrm{C}\end{array}$ \\
\hline $\begin{array}{l}\text { Pinned } \\
\text { foam }\end{array}$ & $\begin{array}{l}\text { Rohacell 31 }+ \text { pins at 30 } \\
12 \mathrm{~mm} \text { thick }\end{array}$ & SE70 Gurit & SA80 & $\begin{array}{l}\text { Autoclave 1 atm } \\
120^{\circ} \mathrm{C}\end{array}$ \\
\hline
\end{tabular}

Table 1. Materials tested.

\begin{tabular}{|c|c|c|}
\hline Panel & $\begin{array}{c}\text { Total force (sum of 4 load cell } \\
\text { measurements), kN }\end{array}$ & $\begin{array}{c}\text { Central displacement of lower } \\
\text { skin, } \mathrm{mm}\end{array}$ \\
\hline 1 & $14.9,14.7,14.6$ & $32,33,32$ \\
\hline 2 & $14.5,15.1,14.2$ & $31,31,31$ \\
\hline
\end{tabular}

Table 2. Results from repeat tests on two honeycomb panels, drop height $2 \mathrm{~m}, 18.8 \mathrm{~kg}$ ball. 


\section{FIGURE HEADINGS}

Figure 1. Slamming impact, core crushing after medicine ball impact

Figure 2. Pinned foam core structure. Detail of unit cell with four pins (upper), and distribution in sandwich (lower).

Figure 3. Tensile fracture surfaces, left pinned foam, right honeycomb.

Figure 4. Test set-up. Upper: Support frame and $18.8 \mathrm{~kg}$ ball on one metre square panel

Figure 5. Representative stress-strain curves, quasi-static compression tests.

Figure 6. Mean strength values, quasi-static tests (error bars indicate standard deviations).

Figure 7. Influence of core thickness and core density on energy to first damage, honeycomb core, a) OX $64 \mathrm{~kg} / \mathrm{m}^{3}$, b) OX $20 \mathrm{~mm}$ thick.

Figure 8. Impact tests performed; Grey indicates undamaged, black indicates panel damaged.

Figure 9. Damage observed after impact

a) Honeycomb, $3 \mathrm{~m} 18.8 \mathrm{~kg}$

b) Foam core, $1 \mathrm{~m} 18.8 \mathrm{~kg}$

c) Pinned foam core, $5 \mathrm{~m} 26 \mathrm{~kg}$

Figure 10. Load and central displacement recordings, a) honeycomb, b) pinned foam, for $18.8 \mathrm{~kg}$ one metre drop tests.

Figure 11. Recorded data from tests versus impact energy.

a) Maximum loads (sum of four load cells)

b) Central displacements

Figure 12. Influence of drop height on contact zone area. Images show ball form and correspond to maximum ball compaction for two drop heights onto pinned foam core sandwich. 


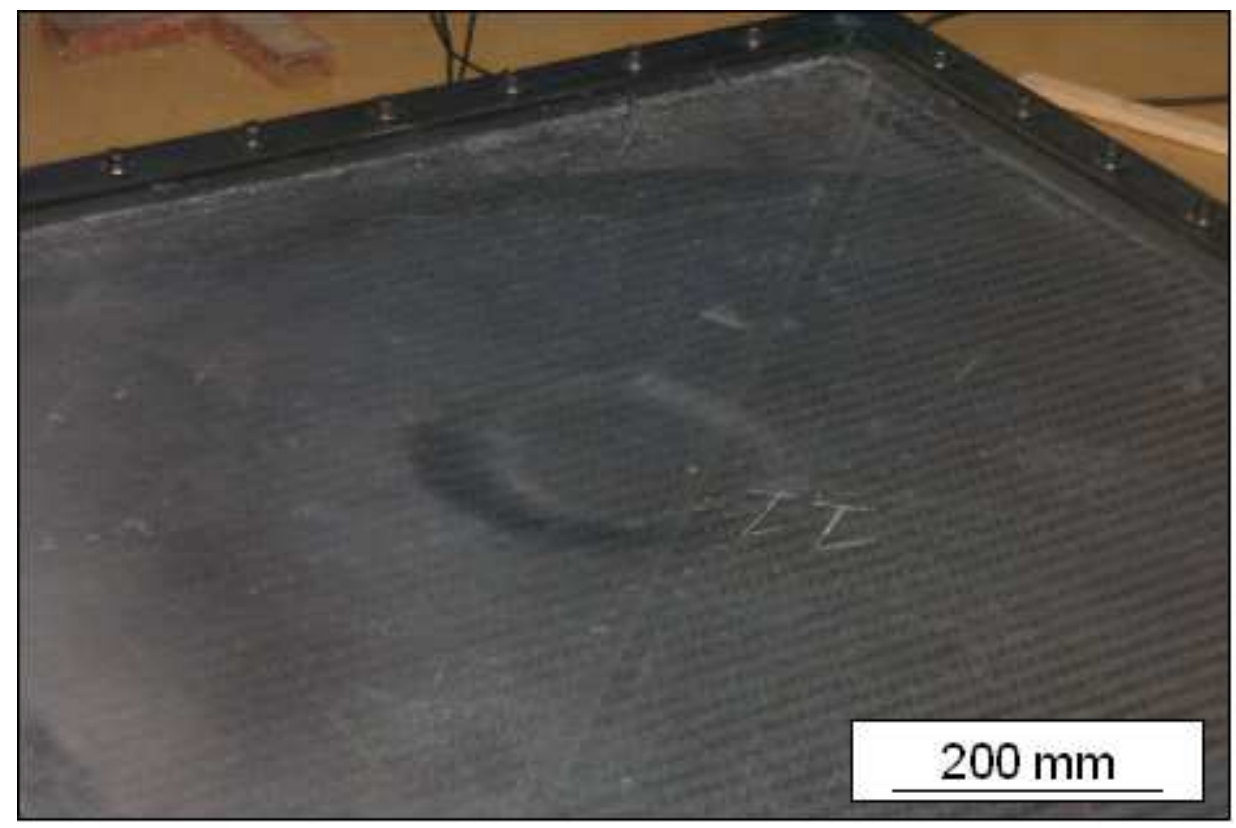

Figure 1. Slamming impact, core crushing after medicine ball impact
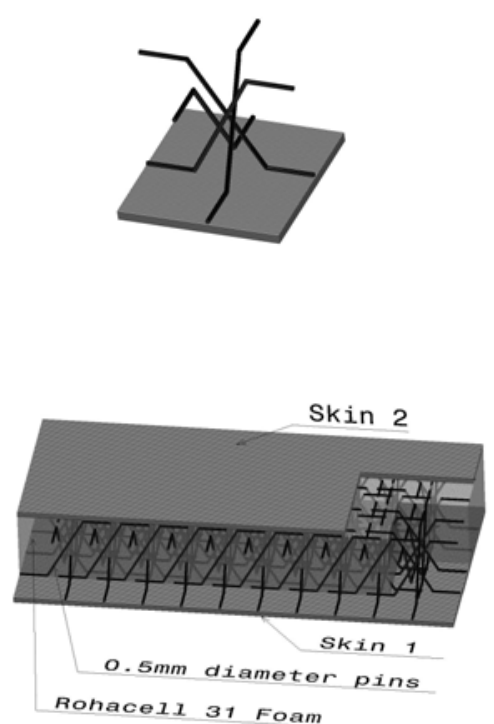

Figure 2. Pinned foam core structure. Detail of unit cell with four pins (upper), and distribution in sandwich (lower). 


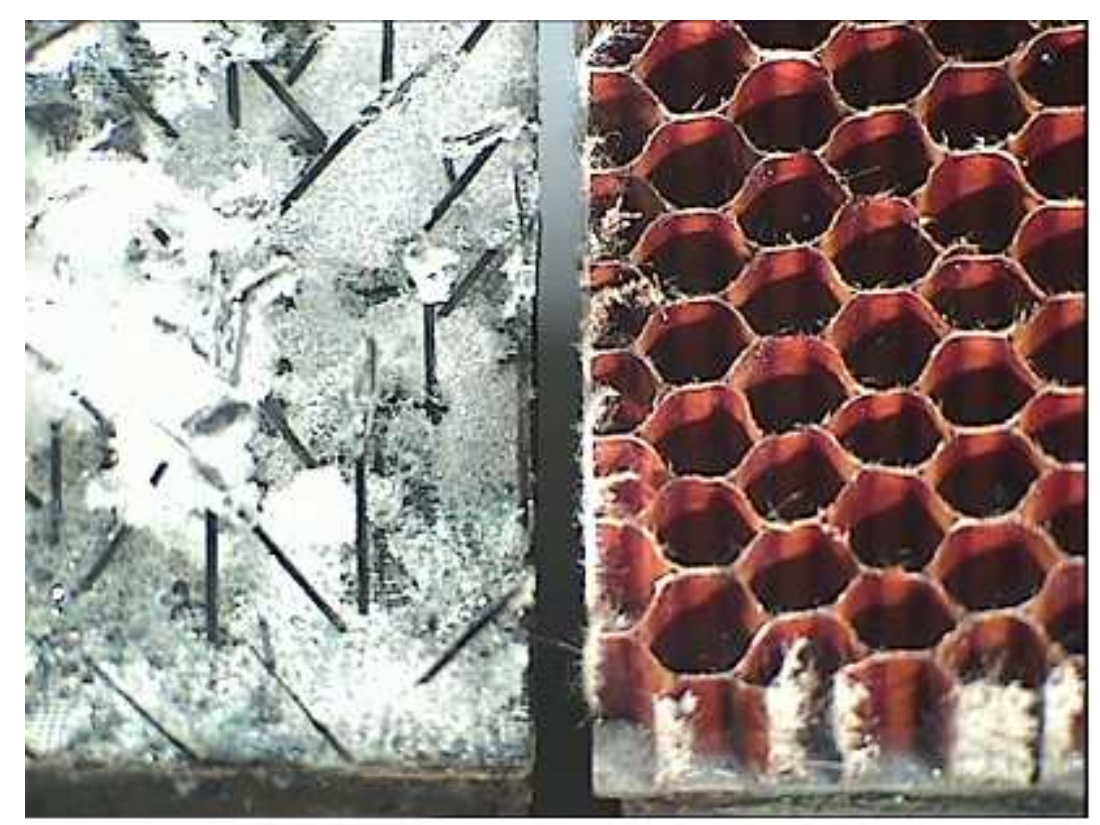

\section{$5 \mathrm{~mm}$}

Figure 3. Tensile fracture surfaces, left pinned foam, right honeycomb.

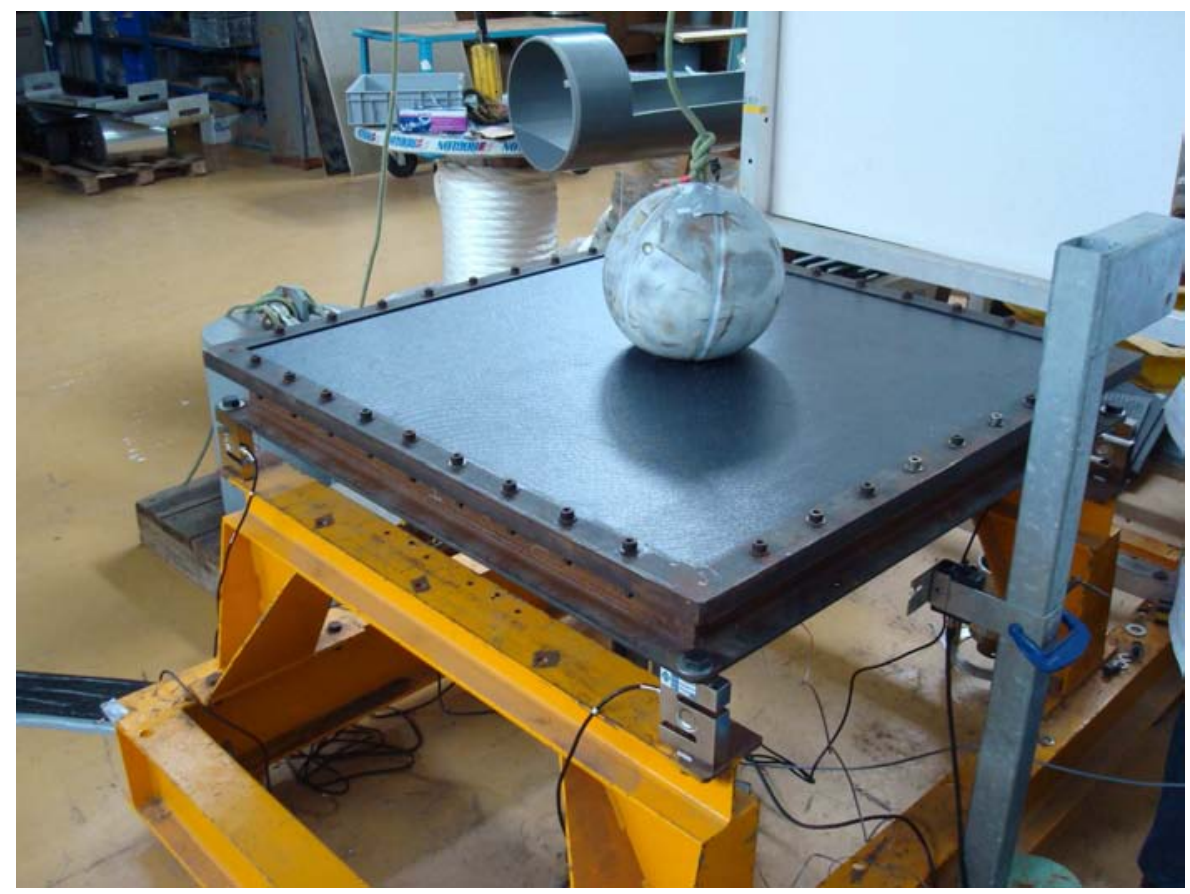

Figure 4. Test set-up. Upper: Support frame and $18.8 \mathrm{~kg}$ ball on one metre square panel 
Compression response, sandwich

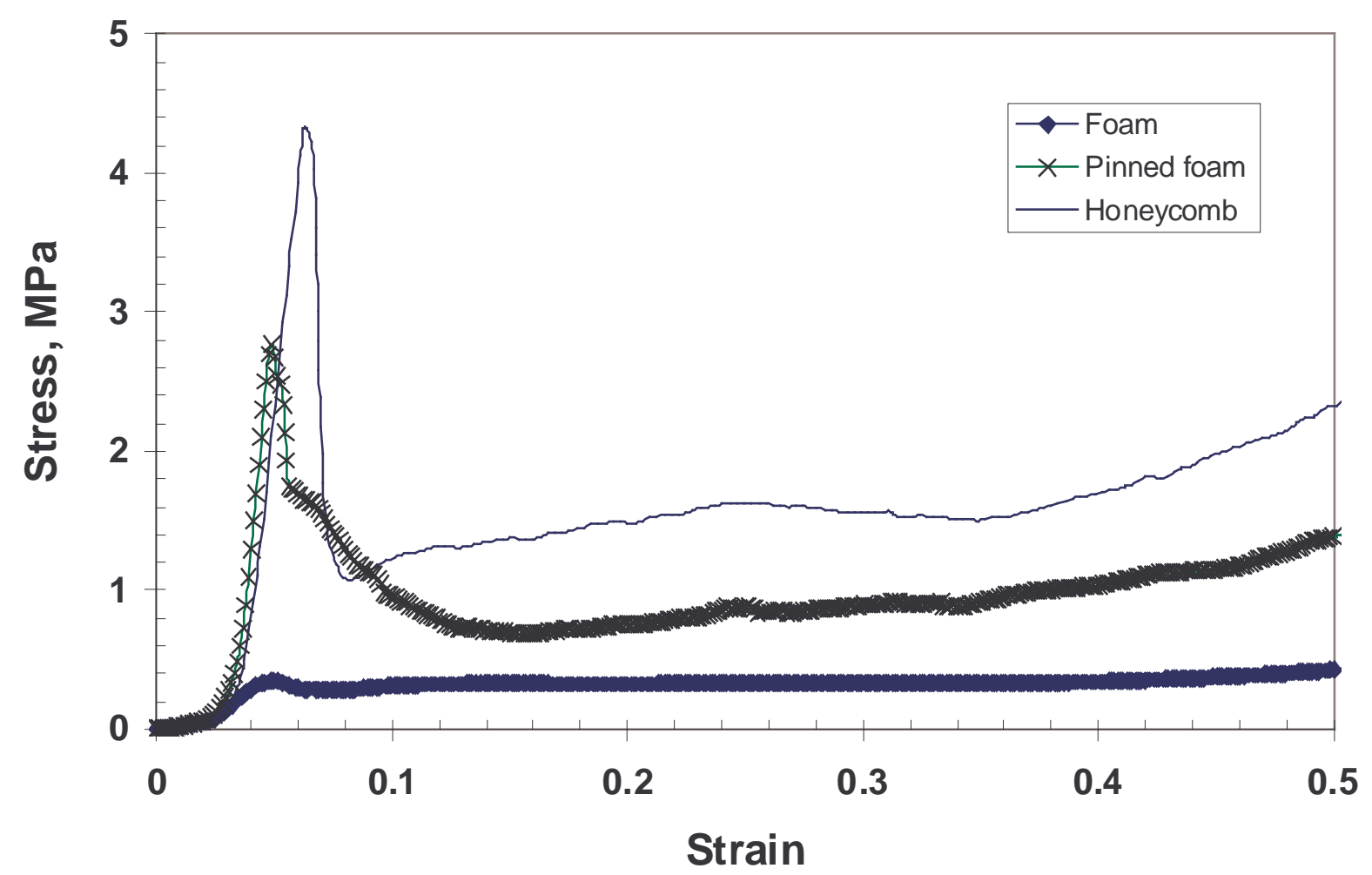

Figure 5. Representative stress-strain curves, quasi-static compression tests.

Strength comparison, sandwich $1 \mathrm{~mm} / \mathrm{min}$.

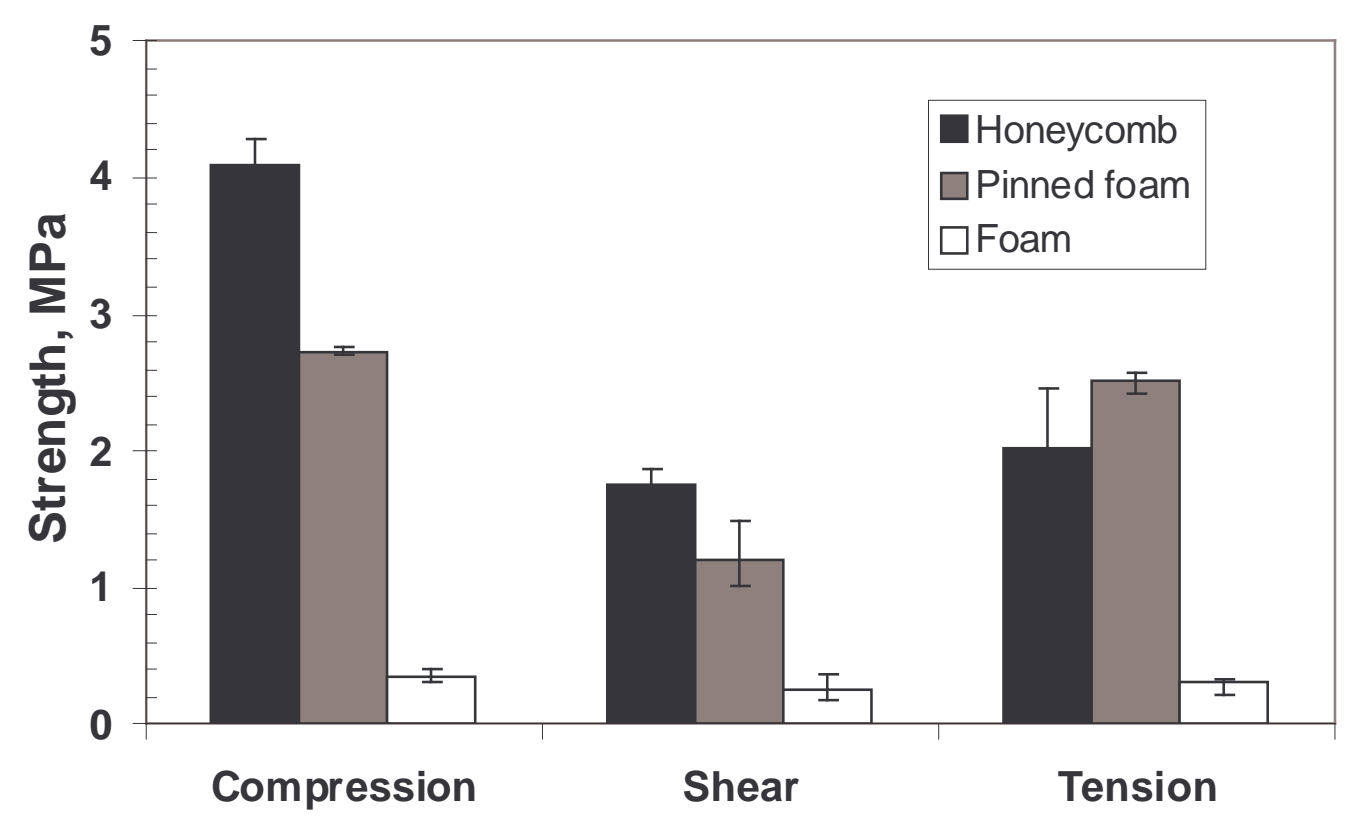

Figure 6. Mean strength values, quasi-static tests (error bars indicate standard deviations). 
a) Core Thickness

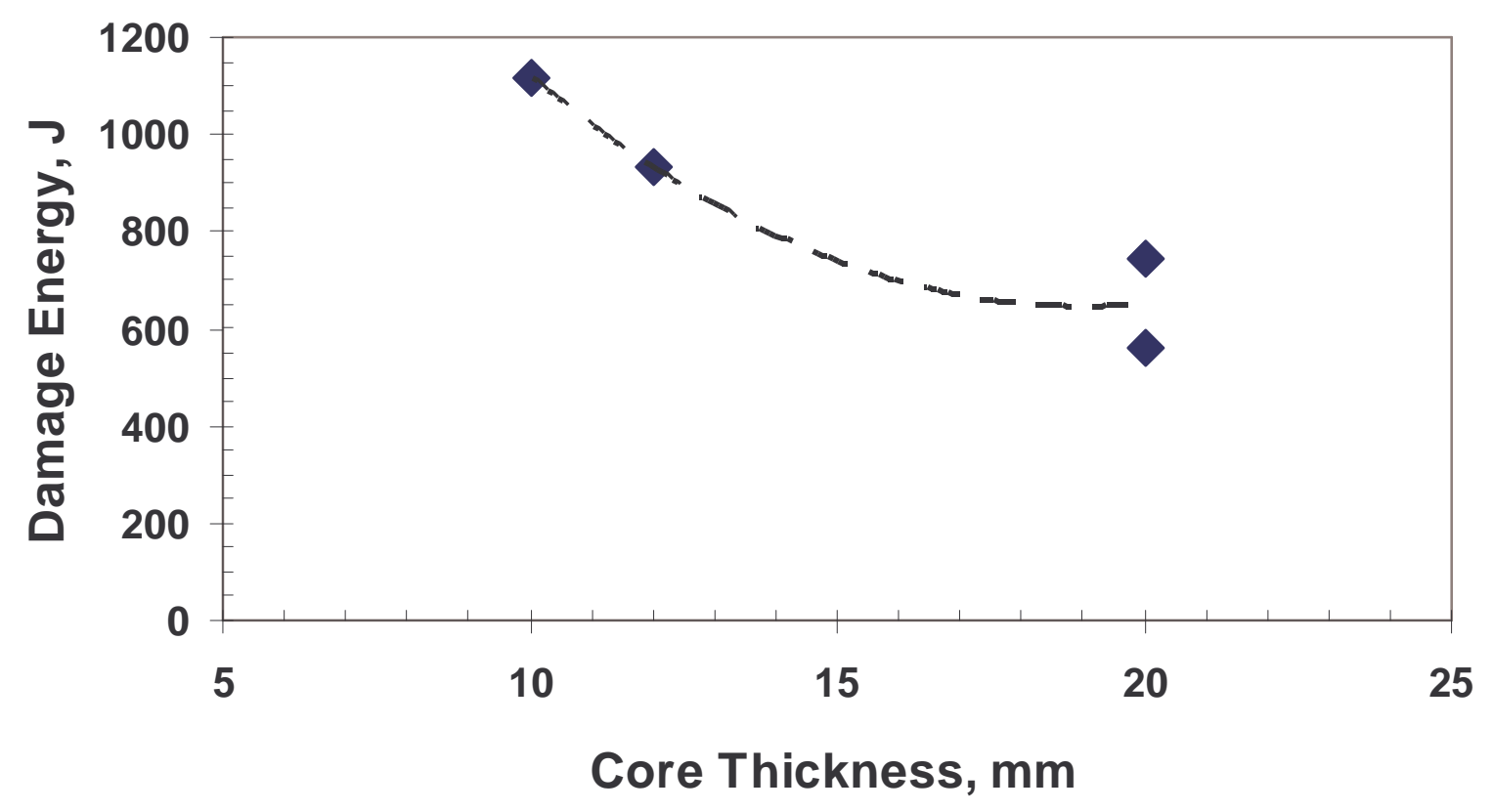

b) Core Density

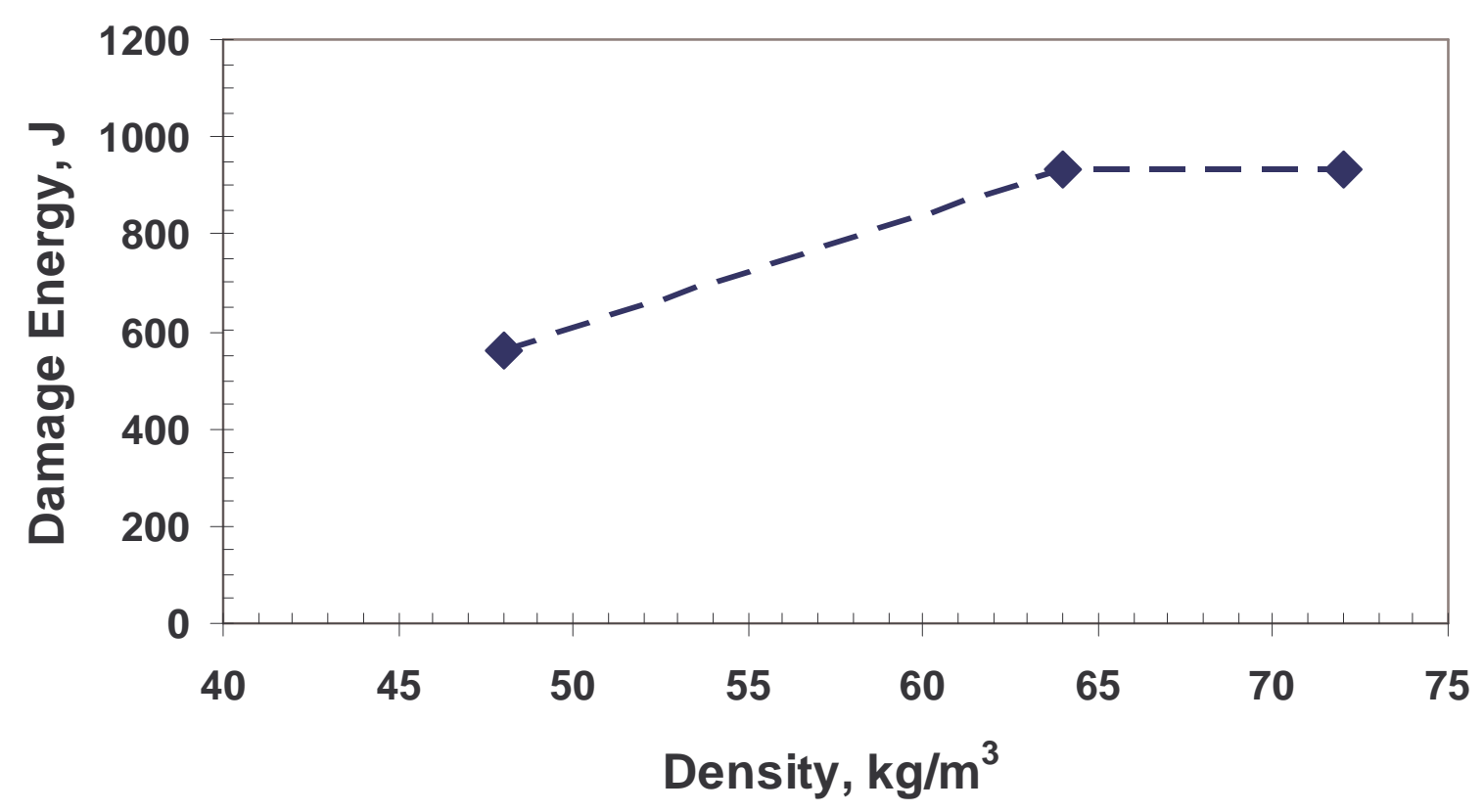

Figure 7. Influence of core thickness and core density on energy to first damage, honeycomb core, a) OX $64 \mathrm{~kg} / \mathrm{m}^{3}$, b) OX $20 \mathrm{~mm}$ thick. 


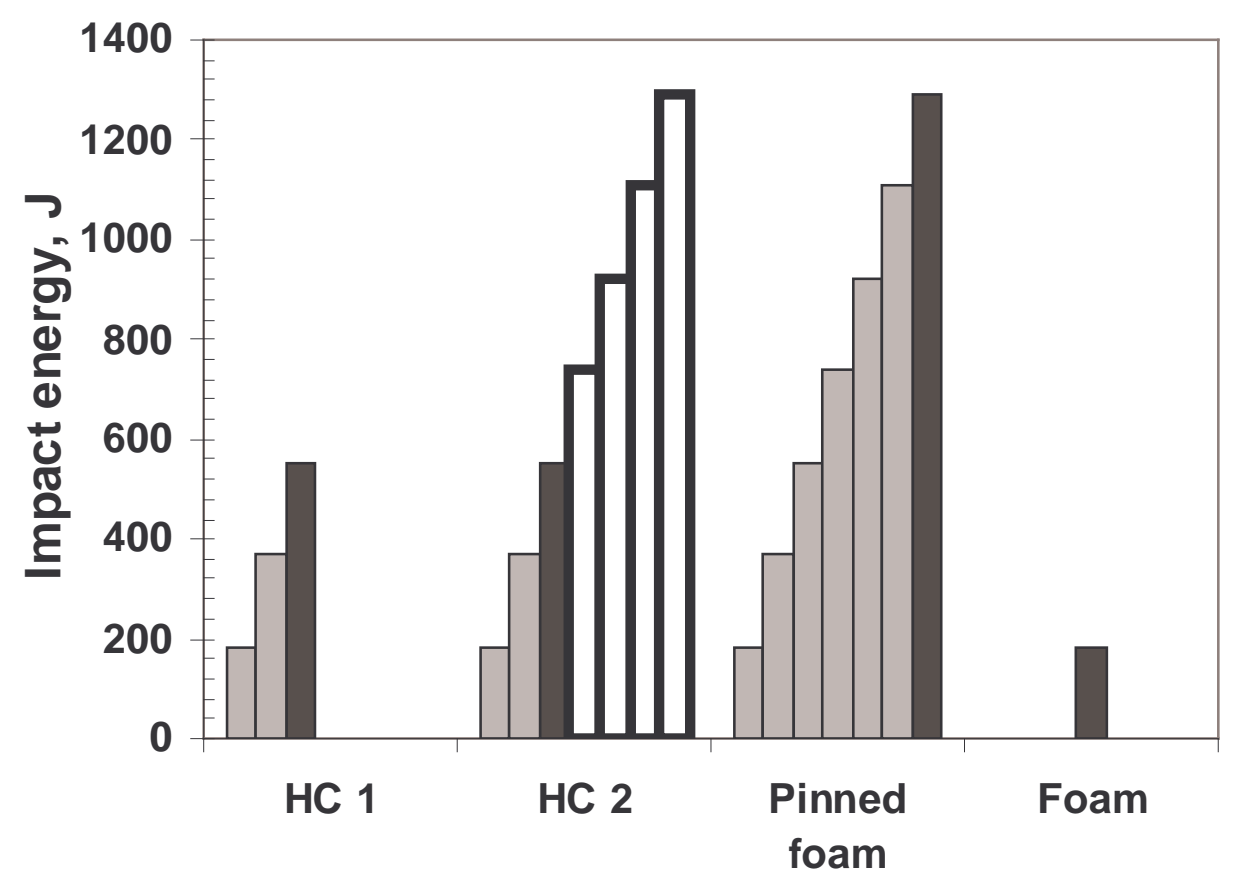

Figure 8. Impact tests performed; HC: Honeycomb. Grey indicates undamaged, black indicates first panel damage noted. 

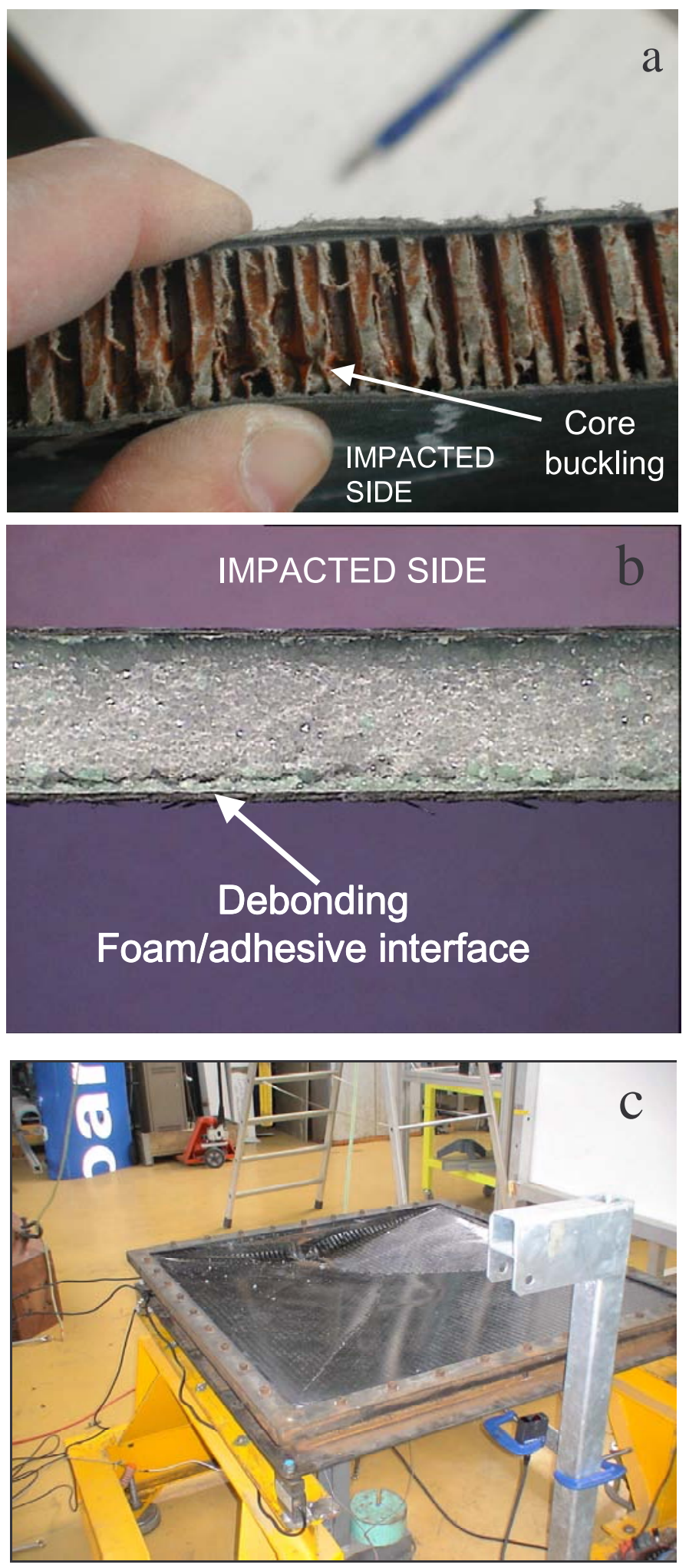

Figure 9. Damage observed after impact

a) Honeycomb, $3 \mathrm{~m} 18.8 \mathrm{~kg}$

b) Foam core, $1 \mathrm{~m} 18.8 \mathrm{~kg}$

c) Pinned foam core panel, $5 \mathrm{~m} 26 \mathrm{~kg}$ 
a) Honeycomb $64 \mathrm{~kg} / \mathrm{m}^{3}$

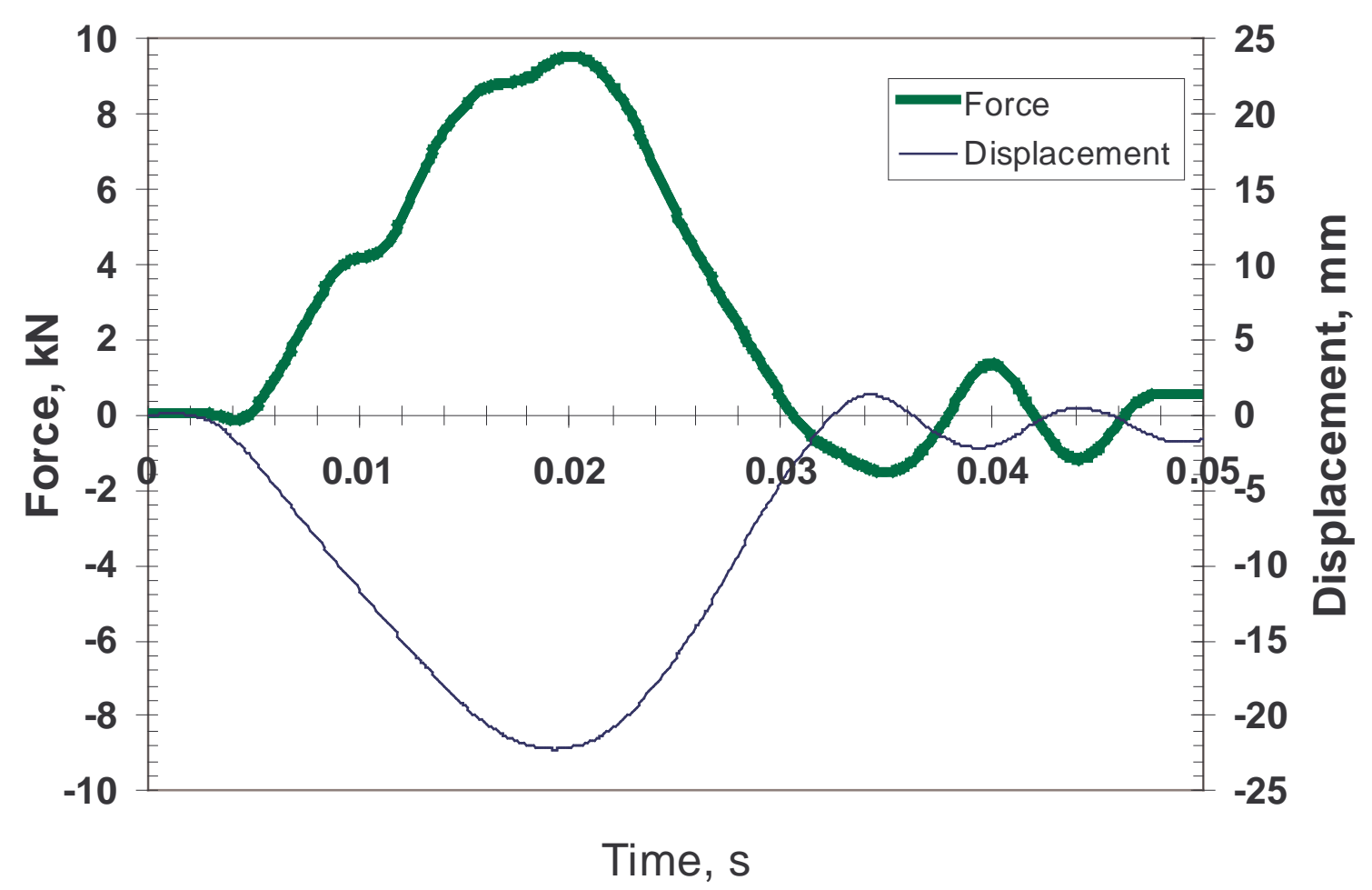

b) Pinned foam

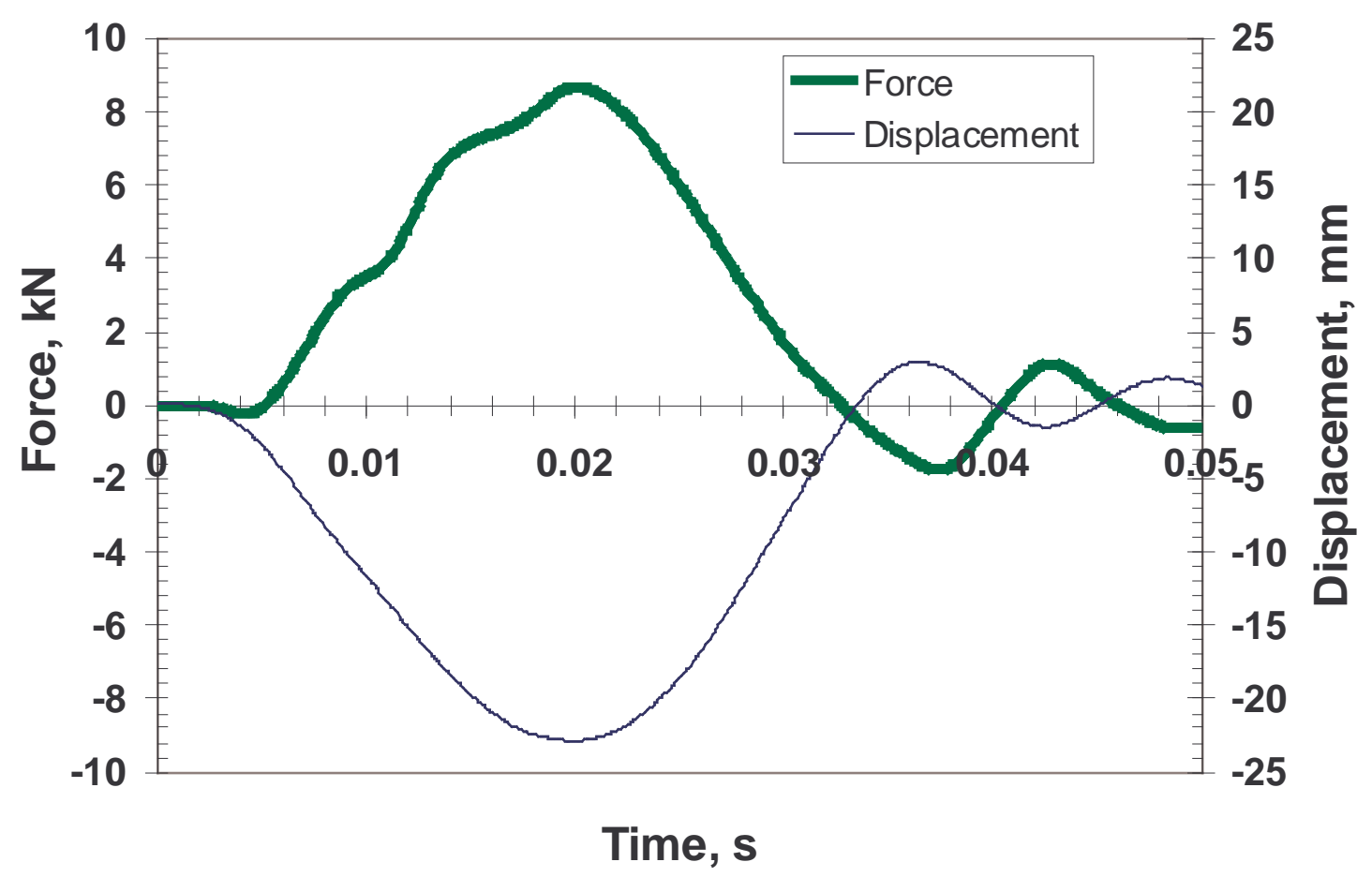

Figure 10. Load and central displacement recordings, a) honeycomb, b) pinned foam, for $18.8 \mathrm{~kg}$ one metre drop tests. 


\section{a) Force}

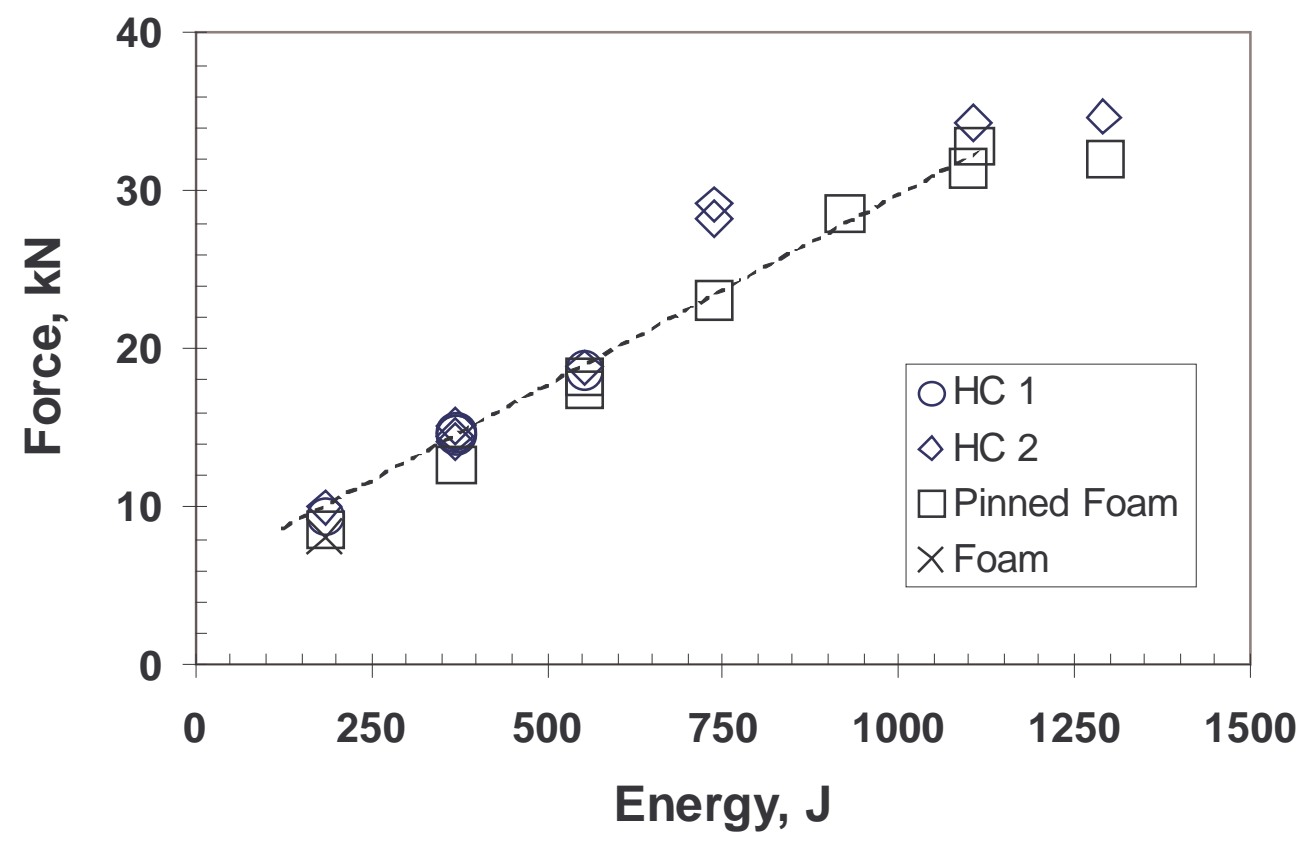

b) Central displacement

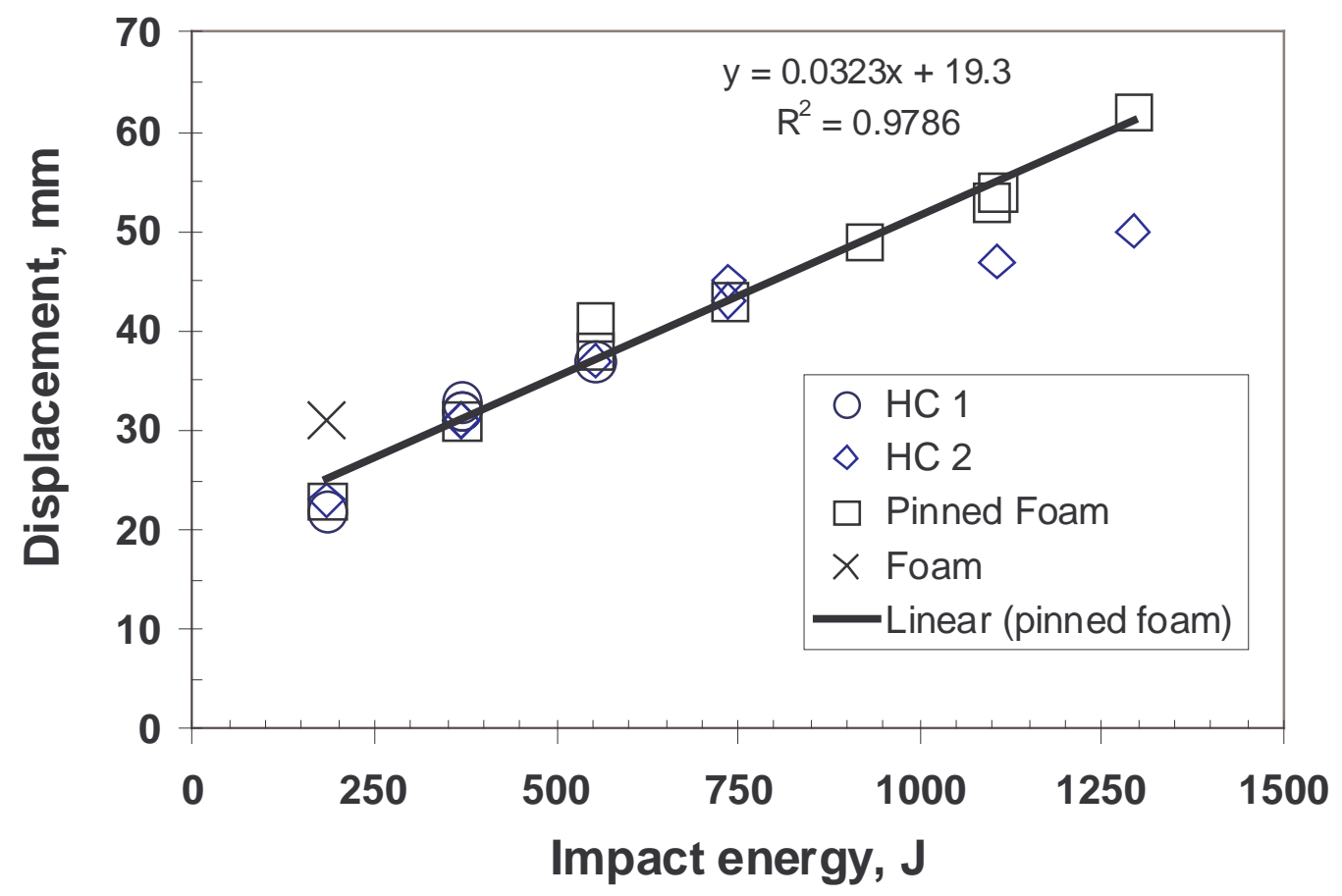

Figure 11. Recorded data from tests versus impact energy.

a) Maximum loads (sum of four load cells)

b) Central displacements 


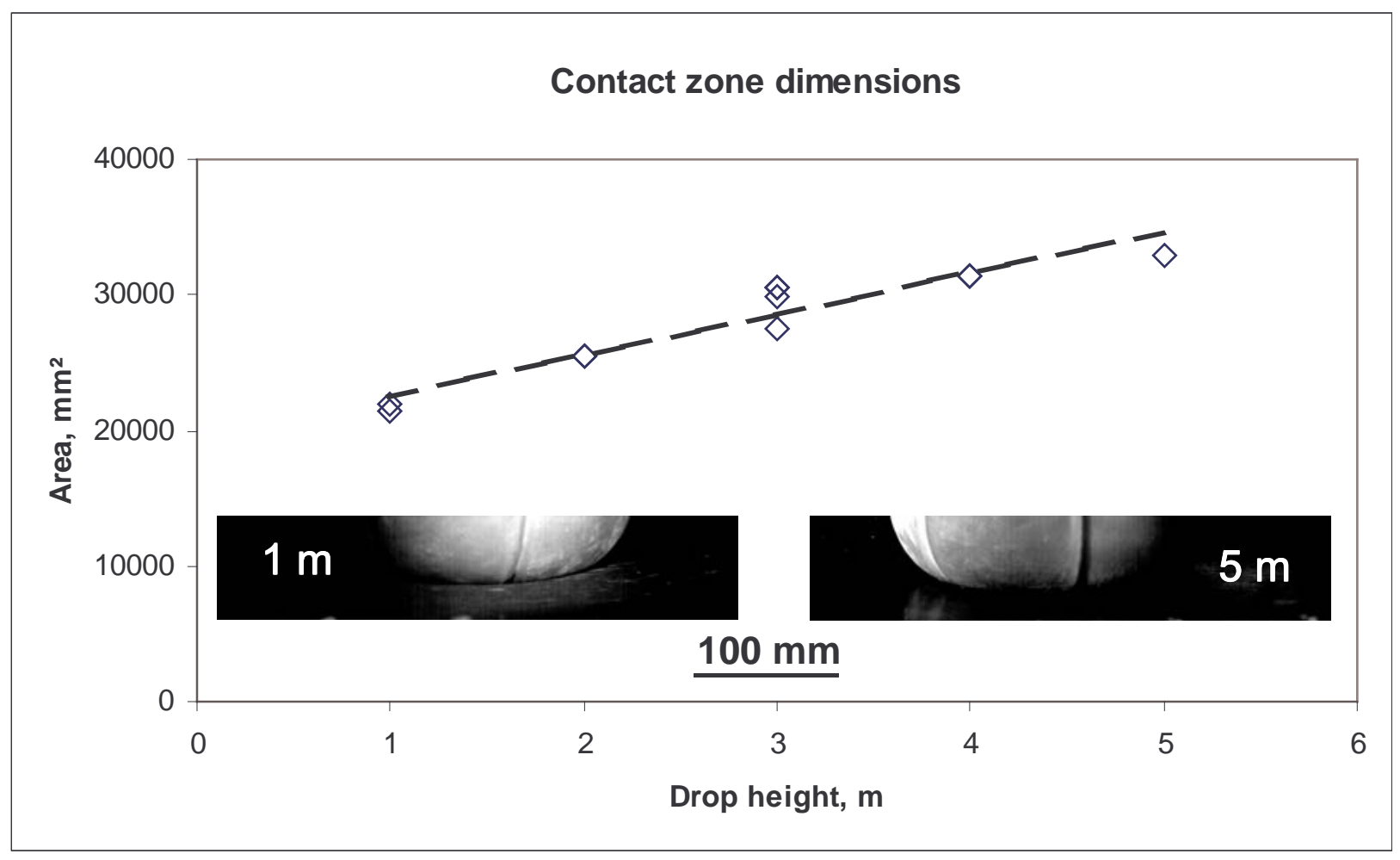

Figure 12. Influence of drop height on contact zone area. Images show ball form and correspond to maximum ball compaction for two drop heights onto pinned foam core sandwich. 